\title{
LIBERAÇÃO DO ABORTO: OPINIÃO DE ESTUDANTES DE MEDICINA E DE DIREITO, SÃO PAULO, BRASIL
}

\author{
Affonso Renato Meira"* \\ Flávio Roberto Carvalho Ferraz **
}

\begin{abstract}
MEIRA, A.R. \& FERRAZ, F.R.C. Liberação do aborto: opiniāo de estudantes de Medicina e de Direito, São Paulo, Brasil. Rev. Saúde públ, S.Paulo, 23:465-72, 1989.

RESUMO: São apresentados os resultados de um levantamento realizado com o objetivo de conhecer a opinião de grupos ligados à problemática do abortamento em razão de sua formação universitária e da idade. Foi levantada a opinião de 155 estudantes de Medicina e de-141 de Direito, mediante questionário, distriburdo em sala de aula, contendo três indagações a respeito do assunto. Seis $(2,1 \%)$ estudantes não emitiram opinião, $142(48,4 \%)$ responderam favoravelmente à liberação e $148(49,5 \%)$ mostraram-se contrários. Destes, somente $12(4,1 \%)$ negaram o abortamento em qualquer hipótese. A análise estatística não mostrou significancia nas diferenças, ao nível de $5 \%$. Os resultados obtiđos permitiram inferir que nos grupos existia uma divisão paritária de opinióes sobre a liberação do abortamento. Analisados em relação ao curso freqủentado e ao sexo, verificou-se que os resultados apresentavam a mesma divisåo.
\end{abstract}

DESCRITORES: Aborto legal. Conhecimentos, atitudes e prática. Estudantes.

\section{INTRODUÇÃO}

A questão do aborto sempre ocupou lugar de destaque na esfera das polêmicas sociais, que envolvem uma ampla e complexa área que compreende desde a ciência até a religião, passando pela ética, pela política e pelos aspectos jurídicos. É possível remontar as discussões sobre este tema a antiguidade e a toda a história de um modo geral. Um apanhado das preocupaçōes com o aborto através da historia mostra que já os hebreus dispunham de artigos em seu código de leis que puniam (em alguns casos até mesmo com a pena de morte), aqueles que provocassem um aborto ${ }^{2}$. Aristóteles, que em princípio se mostrara contrário à prática do aborto, acabou por admití-la em casos de excesso de população, desde que o embriảo ainda não tivesse sensibilidade nem vida. Esta questão, aliás, tornou-sc candente mais tarde na filosofia e na teologia, quando retomada por Santo Agostinho e posteriormente por Santo Tomás de Aquino 2 . De acordo com o apanhado histórico de Hojda ${ }^{2}$, Santo Agostinho, na trilha aberta por Aristóteles, diferenciava o foetus formatus do foetus informatus, tendo o primeiro já recebido a alma, ao contrário do segundo.

Durante todo o Império Romano, a questão do aborto tamberm foi tratada, tanto no âmbito social como no âmbito jurídico. Não era considerado crime no início, pois o feto era tido como parte integrante do corpo materno (portio viscerum matris), sendo pouco a pouco considerado prática imoral, até que, com o advento do cristianismo, foi definitivamente proibido. O que mostra a história, de tóda forma, é que, liberado ou proibido, o aborto foi uma prática social constante, aparecendo hoje em dia como um dos mais sérios problemas de saúde pública. Schor ${ }^{7}$ estima que o número de casos de aborto no país pode chegar a quatro milhóes por ano, o que representa a quarta causa de mortalidade materna. Meira ${ }^{4}$, em pesquisa realizada na cidade de San-

- Apresentado no I Congresso Pan-Americano de Reproduçāo Humana e XIII Congresso de Reprodução Humana, Natal, RN, 1988.

- Departamento de Medicina Legal, Etica Médica e Modicina Social e do Trabalho da Faculdade de Medicina da Universidade de Sáo Paulo (Instituto Oscar Freire) - Rua Teodoro Sampaio, 115 - 05405 - São Paulo, SP - Brasil. 
tos (SP), mostrou que $24,3 \%$ das mulheres entrevistadas já haviam sofrido pelo menos um aborto espontâneo, e que $15,5 \%$ já haviam praticado pelo menos um aborto provocado. Esse mesmo autor $^{4}$ verificou que entre as mulheres férteis e casadas $32,6 \%$ haviam sofrido ao menos um abortamento. Tais dados permitem ter uma noção do problema no Brasil.

As legislações que se encontram em todos os países têm, umas mais e outras menos rapidamente, acompanhado as constantes mudanças e evoluçóes sociais e cientificas. Assim é que muitos países vêm modificando suas legislações relativas à prática do abortamento, sendo que, em inúmeros deles, tal prática foi liberada de maneira ampla. Em outros, ela é permitida em apenas alguns casos especiais. Países como a França e a Itália, por exemplo, já admitiam na legislação anterior a atual a prática do abortamento terapêutico ${ }^{2}$, isto $e$, aquele realizado quando a gravidez apresenta um risco de vida ou de saúde para a mulher. Hoje em dia as discussőes a respeito da liberação ou da restrição do aborto se dão em um terreno mais social e político do que propriamente científico. Trata-se de uma questão polêmica, localizada em um domínio onde a argumentaçáo racional e científica defronta-se, em um verdadeiro embate, com a argumentaçăo de cunho religioso e com toda sorte de preconceitos culturais e sociais. Isto porque, na esfera da ciência, e especialmente na medicina, existe um nível de desenvolvimento suficiente năo só para a prática em si do abortamento com as condições normais de segurança, como para a deteç̧ão mais minuciosa de casos em que ele se faz necessário. Rodger e
Baird $^{6}$ há pouco descreveram uma alternativa segura e efetiva ao abortamento cirúrgico, pela administração oral de uma combinação de mifepristone (um 19 norsteroide de síntese anti-progesterona) e gemeprost. Da mesma forma, Maria e Stampi ${ }^{3}$, após certificarem-se da eficiência da mifepristone como abortivo, conseguiram, pela associação do RU 486 com um análogo de PGE2, a sulprostone, diminuir de forma eficaz os efeitos secundários decorrentes deste método de abortamento. $O$ processo de abortamento evoluiu acompanhando o desenvolvimento da medicina em geral. E, ao lado dele, desenvolveram-se também as técnicas de diagnóstico de defeitos e lesões no concepto, como a amniocentese, a biópsia placentária e a ultrassonografia. "Camadas sociais de posse desses dados podem considerar válido o abortamento, impedindo o nascimento de um ser anormal"6. Trata-se aqui da modalidade de aborto, denominado "aborto eugênico" ou "piedoso", que pode ser definido como aquele "praticado por indicação médica em razão da grande probabilidade, ou mesmo da certeza, de que a criança por nascer padeça de uma séria anomalia, deformação ou enfermidade grave e incurável, somática ou psíquica, por causa de herança mórbida transmitida por um ou por ambos os genitores, ou por causa de grave dano ou lesão sofrida durante a gravidez"2

Esta modalidade de aborto não é permitida pela lei brasileira. No entanto, na parte especial do Código Penal, aprovado em 1983, mas ainda não em vigor, esta modalidade é admitida. O atual Código Penal Brasileiro, em vigor, diz, em seu artigo 128 , que năo se pune 0 aborto praticado

TABELA 1

Distribuição das respostas dos estudantes de Medicina e de Direito da Universidade de São Paulo, de acordo com o sexo e a sua opinião sobre a liberação do abortamen to em enque te realizada em 1988*

\begin{tabular}{lccccccccc}
\hline \multirow{2}{*}{ Sexo } & \multicolumn{2}{c}{ Sim } & \multicolumn{2}{c}{ Não } & \multicolumn{2}{c}{ Sem Opinião } & \multicolumn{2}{c}{ Total** } \\
\cline { 2 - 9 } & No & $\%$ & No & $\%$ & No & $\%$ & No & $\%$ \\
\hline Masculino & 76 & 46,3 & 84 & 51,2 & 4 & 2,5 & 164 & 100,0 \\
Feminino & 65 & 51,2 & 66 & 47,2 & 2 & 1,6 & 127 & 100,0 & 100,0 \\
Total & 141 & 48,4 & 144 & 49,5 & 6 & 2,1 & 291 & \\
\hline
\end{tabular}

* Resposta à questão 1 - "Na sua opinião, independentemente do que trata a legislação em vigor, o abortamento poderia ser realizado sem restrições legais?"

** Nâo foram incluídos 5 entrevistados que não informaram o sexo. 


\section{TABELA 2}

Distribuição das respostas dos estudantes de Medicina da Universidade de São Paulo, de acordo com o sexo e a sua opinião sobre a liberação do abortamen to em enquete realizada em 1988.

\begin{tabular}{lccccccccc}
\hline \multirow{2}{*}{ Sexo } & \multicolumn{2}{c}{ Sim } & \multicolumn{2}{c}{ Não } & \multicolumn{2}{c}{ Sem Opinião } & \multicolumn{2}{c}{ Total* } \\
\cline { 2 - 9 } & No & $\%$ & No & $\%$ & No & $\%$ & No & $\%$ \\
\hline Masculino & 45 & 48,9 & 44 & 47,8 & 3 & 3,3 & 92 & 100,0 \\
Feminino & 27 & 45,8 & 30 & 50,8 & 2 & 3,4 & 59 & 100,0 & 100,0 \\
Total & 72 & 47,7 & 74 & 49,0 & 5 & 3,3 & 151 & 100 \\
\hline
\end{tabular}

* Não foram incluídos 4 en trevistados que nāo informaram o sexo.

TABELA 3

Distribuição das respostas dos estudantes de Direito da Universidade de São Paulo, de acordo com o sexo e a sua opinião sobre a liberação do abortamento em enquete realizada em 1988.

\begin{tabular}{lcccccccc}
\hline \multirow{2}{*}{ Sexo } & \multicolumn{2}{c}{ Sim } & \multicolumn{2}{c}{ Não } & \multicolumn{2}{c}{ Sem Opinião } & \multicolumn{2}{c}{ Total* } \\
\cline { 2 - 9 } & No & $\%$ & No & $\%$ & No & $\%$ & No & $\%$ \\
\hline Masculino & 31 & 43,0 & 40 & 55,6 & 1 & 1,4 & 72 & 100,0 \\
Feminino & 38 & 55,9 & 30 & 44,1 & 0 & 0 & 68 & 100,0 \\
Total & 69 & 49,3 & 70 & 50,0 & 1 & 0,7 & 140 & 100,0 \\
\hline
\end{tabular}

* Não foi incluído 1 entrevistado que não informou o sexo.

TABELA 4

Distribuição das respostas dos estudantes de Medicina e de Direito da Universidade de São Paulo, de acordo com o sexo e a sua opinião a respeito de a quem cabe decidir sobre a realização do abortamen to*.

\begin{tabular}{|c|c|c|c|c|c|c|c|c|}
\hline \multirow{3}{*}{ Sexo } & \multicolumn{8}{|c|}{ Tipo de Resposta } \\
\hline & \multicolumn{2}{|c|}{$\grave{A}$ Mulher } & \multicolumn{2}{|c|}{ Ao Casal } & \multicolumn{2}{|c|}{ Outros } & \multicolumn{2}{|c|}{ Total $* *$} \\
\hline & No & $\%$ & No & $\%$ & No & $\%$ & No & $\%$ \\
\hline Masculino & 30 & 39,5 & 43 & 56,6 & 3 & 3,9 & 76 & 100,0 \\
\hline Feminino & 25 & 38,5 & 36 & 55,4 & 4 & 6,1 & 65 & 100,0 \\
\hline Total & 55 & 39,0 & 79 & 56,0 & 7 & 5,0 & 141 & 100,0 \\
\hline
\end{tabular}

* Somente para os que responderam sim à questão 1 (ver rodapé : Tabela 1)

** Não foi incluído um en trevistado que não informou o sexo.

por médico somente em duas situaçōes: no caso de aborto necessário ("se não há outro meio de salvar a vida da gestante") e no caso de gravidez resultante de estupro ("se a gravidez resulta de estupro e o abortamento é precedido de consentimento da gestante ou, quando incapaz, de seu representante legal") 5 . Assim mesmo, a expressão "náo se pune" dá margem para se considerar 


\section{TABELA 5}

Distribuição das respostas dos estudantes de Medicina da Universidade de São Paulo, de acordo com o sexo e sua opinião a respei to de a quem cabe decidir sobre a realização do abortamen to*.

\begin{tabular}{|c|c|c|c|c|c|c|c|c|}
\hline \multirow{3}{*}{ Sexo } & \multicolumn{8}{|c|}{ Tipo de Resposta } \\
\hline & \multicolumn{2}{|c|}{ À Mulher } & \multicolumn{2}{|c|}{ Ao Casal } & \multicolumn{2}{|c|}{ Outros } & \multicolumn{2}{|c|}{ Total ** } \\
\hline & No & $\%$ & N? & $\%$ & No & $\%$ & No & $\%$ \\
\hline Masculino & 9 & 20,0 & 33 & 73,3 & 3 & 6,7 & 45 & 100,0 \\
\hline Feminino & 9 & 33,3 & 15 & 55,6 & 3 & 11,1 & 27 & 100,0 \\
\hline Total & 18 & 25,0 & 48 & 66,7 & 6 & 8,3 & 72 & 100,0 \\
\hline
\end{tabular}

Somente aos que responderam sim à questão 1 (ver rodapé: Tabela 1)

* Não foi incluído um entrevistado que não informou o sexo.

TABELA 6

Distribuição das respostas dos estudantes de Direito da Universidade de São Paulo, de acordo com o sexo e sua opinião a respeito de a quem cabe decidir sobre a realização do abortamen to*.

\begin{tabular}{|c|c|c|c|c|c|c|c|c|}
\hline \multirow{3}{*}{ Sexo } & \multicolumn{8}{|c|}{ Tipo de Resposta } \\
\hline & \multicolumn{2}{|c|}{ À Mulher } & \multicolumn{2}{|c|}{ Ao Casal } & \multicolumn{2}{|c|}{ Outros } & \multicolumn{2}{|c|}{ Total } \\
\hline & $N ?$ & $\%$ & N! & $\%$ & Nọ & $\%$ & Nọ & $\%$ \\
\hline Masculino & 21 & 67,7 & 10 & 32,3 & 0 & - & 31 & 100,0 \\
\hline Feminino & 16 & 42,1 & 21 & 55,3 & 1 & 2,6 & 38 & 100,0 \\
\hline Total & 37 & 53,6 & 31 & 44,9 & 1 & 1,5 & 69 & 100,0 \\
\hline
\end{tabular}

* Somente aos que responderam sim à questão 1 (ver rodapé: Tabela 1)

que, para a legislação, qualquer forma de abortamento continua tendo um "status" de crime, ainda que não passível de punição.

No caso de aborto eugênico, um dos argumentos usados para sua contestação foi dado por Hungria e Bruno ${ }^{2}$ que, ao se posicionarem contra sua legalização, afirmavam que a ciência da herança ainda não havia atingido o nível de desenvolvimento suficiente para dar a palavra definitiva nesta questão. De fato, a afirmação podia ser procedente para a época em que foi feita. No entanto, os avanços científicos hoje disponíveis mostram que ela não é mais válida.

As mudanças na legislaçăo não estão, é verdade, condicionadas somente a avanços científi- cos, sendo elas resultado de um complexo emaranhado de conjunções sociais, económicas e políticas, ao lado, também, das científicas. Uma outra variante que se relaciona com este processo é a chamada opinião pública. Exemplo disso é a polemica deflagrada pela adoçăo do RU 486 (a "pílula do mes seguinte", como foi batizada) na França, polêmica que deixou de ser nacional para se internacionalizar. A sociedade reagiu de forma apaixonada, tendo mesmo havido setores que propuseram um boicote geral aos produtos do laboratório fabricante da pilula abortiva e ameacas de morte a seus diretores. $O$ governo frances, após ter proibido o medicamente ante tamanha pressão, acabou por liberá-lo novamente. $O$ as- 


\section{TABELA 7}

Distribuição das respostas dos estudantes de Medicina e de Direito da Universidade de São Paulo, de acordo com o sexo e sua opinião sobre as eventualidades em que se possa admitir o abortamento*.

\begin{tabular}{|c|c|c|c|c|c|c|}
\hline \multirow{3}{*}{ Eventualidades } & \multicolumn{4}{|c|}{ Sexo } & \multirow{2}{*}{\multicolumn{2}{|c|}{ Total** }} \\
\hline & \multicolumn{2}{|c|}{ Masculino } & \multicolumn{2}{|c|}{ Feminino } & & \\
\hline & No & $\%$ & Nọ & $\%$ & No & $\%$ \\
\hline $\begin{array}{l}\text { Gravidez resultante de ato sexual rea- } \\
\text { lizado mediante violência ou grave } \\
\text { ameaça }\end{array}$ & 75 & 94,9 & 48 & 90,6 & 123 & 93,18 \\
\hline Gravidez de menores de 14 anos & 31 & 39,2 & 22 & 41,5 & 53 & 40,1 \\
\hline Gravidez de incapazes mentais & 49 & 62,0 & 35 & 66,0 & 84 & 63,6 \\
\hline $\begin{array}{l}\text { Gravidez que apresenta risco de vida } \\
\text { ou de saúde para a mulher }\end{array}$ & 72 & 91,1 & 50 & 94,3 & 122 & 92,4 \\
\hline $\begin{array}{l}\text { Existência de certeza ou de alta pos- } \\
\text { sibilidade de a criança nascer com de- } \\
\text { feito grave ou doença incurável }\end{array}$ & 62 & 78,4 & 47 & 88,7 & 109 & 82,6 \\
\hline Outros & 12 & 15,2 & 12 & 22,5 & 24 & 18,2 \\
\hline
\end{tabular}

* Somente para os que responderam não à questão 1 , segundo as even tualidades acima indicados.

** Nâo foram incluídos 3 entrevistados que não informaram o sexo e 12 que responderam não admitir a realização do abortamento em hipótese alguma.

\section{TABELA 8}

Distribuição das respostas dos estudantes de Medicina da Universidade de São Paulo, de acordo com o sexo e sua opinião sobre as eventualidades em que se possa admitir o abortamen to*.

\begin{tabular}{|c|c|c|c|c|c|c|}
\hline \multirow{3}{*}{ Eventualidades } & \multicolumn{4}{|c|}{ Sexo } & & \\
\hline & \multicolumn{2}{|c|}{ Masculino } & \multicolumn{2}{|c|}{ Feminino } & \multicolumn{2}{|c|}{ Total** } \\
\hline & Nọ & $\%$ & № & $\%$ & Nọ & $\%$ \\
\hline $\begin{array}{l}\text { Gravidez resultante de ato sexual rea- } \\
\text { lizado mediante violência ou grave } \\
\text { ameaça }\end{array}$ & 41 & 97,6 & 26 & 92,7 & 67 & 95,7 \\
\hline Gravide $z$ de menores de 14 anos & 16 & 38,1 & 9 & 32,1 & 25 & 35,7 \\
\hline Gravidez de incapazes men tais & 25 & 59,5 & 19 & 67,9 & 44 & 62,6 \\
\hline $\begin{array}{l}\text { Gravidez que apresenta risco de vida } \\
\text { ou de saúde para a mulher }\end{array}$ & 38 & 90,4 & 26 & 92,9 & 64 & 91,4 \\
\hline $\begin{array}{l}\text { Existência de certeza ou de alta pos- } \\
\text { sibilidade de a criança nascer com de- } \\
\text { feito grave ou doença incurável }\end{array}$ & 36 & 85,7 & 24 & 85,7 & 60 & 85,7 \\
\hline Outros & 5 & 11,9 & 6 & 21,4 & 11 & 15,7 \\
\hline
\end{tabular}

* Somente para os que responderam não à questão 1 , segundo as eventualidades acima indicadas.

** Não foram incluídos 3 entrevistados que não informaram o sexo e 4 que responderam não admitir a realizaçāo de um abortamento em hipotese alguma. 
TABLLA 9

Distribuição das respostas dos estudantes de Direito da Universidade de São Paulo, de acordo com o sexo e sua opinião sobre as eventualidades em que se possa admitir o abortamento*.

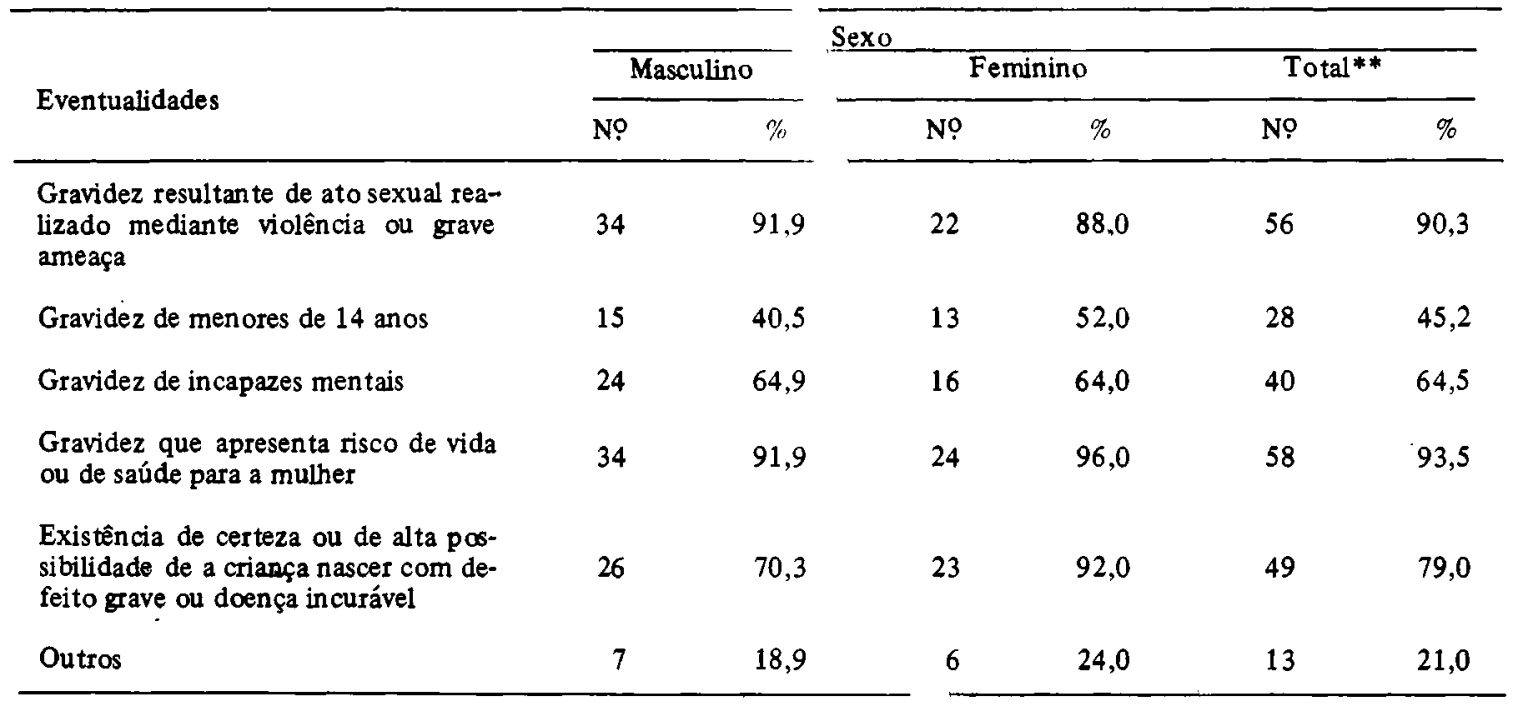

* Somente para os que responderam não à questão 1 , segundo as eventualidades acima indicadas.

** Não foram incluidos 8 entrevistados que responderam não admitir a realização de um abortamento em hipótese alguma.

sunto foi amplamente abordado pela imprensa internacional e tambem pelos jornais e pela televisăo brasileira ${ }^{1}$.

No momento histórico vivido atualmente no Brasil, quando a opiniåo pública esteve voltada ds discussōes em torno da elaboração da nova Constituiçăo, o questionamento da liberação do abortamento ganha vulto.

Cabe, portanto, não só pela importância como pela oportunidade procurar saber o que grupos da sociedade brasileira entendem a respeito. Por isso, o presente levantamento visou a conhecer a opinião de estudantes de quarto ano das Faculdades de Medicina e de Direito da Universidade de Săo Paulo (ambas localizadas na cidade de Såo Paulo) a respeito do aborto.

Foram escolhidos tais estudantes pelos seguintes motivos:

1. Săo estudantes de áreas ligadas à saúde e a legislação, isto $\hat{e}$, estudantes que terăo, pela natureza de seu campo profissional, que lidarem com a questão do aborto, quer na esfera médica, quer na esfera jurldica;

2. Săo estudantes que, estando a cursar o quarto ano, já podem ter alguma opiniáo mais profissional, mesmo que incipiente, a respeito da problemática do aborto; além disso, estão tam- bém próximos do ingresso no mercado de trabalho, o que faz com que os resultados obtidos na pesquisa sejam indicadores da tendência de opinião daqueles que, dentro em breve, serão os profissionais que transitarão nas áreas relacionadas com o aborto;

3. São estudantes jovens que, de certa forma, podem estar envolvidos pessoalmente, de modo mais ou menos intenso com a questão do aborto.

\section{METODOLOGIA}

O levantamento de opiniơes foi realizado por meio de um questionário, respondido por 155 alunos do $4^{\circ}$ ano da Faculdade de Medicina e 141 do $4^{\circ}$ ano diurno da Faculdade de Direito, da Universidade de Săo Paulo, presentes em sala de aula no dia da aplicação, no primeiro semestre letivo de 1988.

O levantamento foi realizado coletivamente após uma breve explicaçẩo como reforço às instruções contidas no questionário. $O$ anonimato foi garantido a quem o quis. Aluno algum negouse a responder, tendo sido o tempo máximo de resposta de aproximadamente $10 \mathrm{~m}$.

Entre os estudantes de Medicina, 92 eram do sexo masculino e 59 do feminino; 148 deles 
declararam-se solteiros e a média de idade foi de 21,7 anos. Quatro deles não informaram o sexo. Entre os estudantes de Direito, 72 eram do sexo masculino e 68 do feminino; 133 deles declararam-se solteiros e a média de idade foi de 21,8 anos. Um deles não informou o sexo.

\section{RESULTADOS}

A distribuição dos estudantes de Medicina e de Direito, de acordo com o sexo e a sua opinião sobre a liberação do abortamento, encontra-se nas Tabelas 1,2 e 3.

A distribuição por sexo e sua opinião a respeito de quem deve decidir sobre a realização do abortamento, encontra-se nas Tabelas 4, 5 e 6.

Quanto às eventualidades em que se pode admitir o abortamento, os resultados encontramse nas Tabelas 7, 8 e 9.

Analisados estatisticamente ao nível de 5\%, os resultados não se mostraram significativamente diferentes, nem entre os estudantes de Medicina e de Direito, nem entre os estudantes do sexo masculino e do sexo feminino.

\section{DISCUSSĀO}

Os resultados mostram que dentre um total de 291 estudantes, somente $12(4,1 \%)$ responderam exalando a opinião de que a permissão para a realização do abortamento devesse ser taxativamente negada. Os restantes dividiram-se praticamente à metade, aceitando uma metade o abortamento sem restrição alguma, e a outra apresentando algumas restrições.

Tal divisão permitiu dois tipos de ilações:

1) Os entrevistados responderam de maneira alienada às indagações. Daí as respostas de aproximadamente $50 \%$ para a liberação sem e com restriçőes, como se fora realizado através de lançamento de moeda para verificar cara e coroa.

2) As respostas mostraram uma real divisão da opinião dos universitários desses grupos a respeito do assunto, chegando mesmo a uma radicalização.

Pelo processo em que foram realizadas as entrevistas e pela atenção que o assunto mereceu, os autores se inclinam pela segunda alternativa. Isso se reforça quando se analisam as respostas dadas à terceira pergunta. Por elas é possível verificar que, apesar de responderem NÃO, existe uma variabilidade de opinião sobre essa negativa. Partindo de uma pequena minoria (4 entre os estudantes de Medicina e 8 entre os estudantes de Direito) que negaram de maneira absoluta a realização do abortamento, chega-se a diversas posições que o admitem, embora de modo mais ou menos restritivo.

Há que se ressaltar que, entre aqueles que admitem a realizaçăo de um abortamento apenas em algumas situaçōes, a maior parte concorda com o teor da legislação brasileira, aceitando o abortamento em casos de gravidez resultante de violência sexual $(93,2 \%)$ ou de gravidez que apresente risco de vida ou de saúde para a mulher $(92,4 \%)$. Outro fator importante foi a aceitação do chamado aborto eugênico por $82,6 \%$ dos entrevistados que só admitem o abortamento em certas situações, pois, diferentemente dos casos acima tratados, esta modalidade de abortamento não é permitida pela lei brasileira.

Outro ponto que merece citação diz respeito à opinião dos estudantes sobre quem deve dẹcidir da realização de um abortamento. Entre os estudantes de Direito apenas $1,4 \%$ responderam que tal decisão cabe a "outros" que não a mulher ou casal. Já entre os estudantes de Medicina este percentual sobe para $8,3 \%$ sendo que estes "outros" foram especificados como o médico pela totalidade dos estudantes que fizeram essa afirmação. A hipótese de que tal resposta deve-se a um posicionamento etnocentrico dos alunos de medicina em relação a aspectos de saúde, não pode ser descartada.

Por fim, outro dado que se destaca é a diferença de opiniões entre os estudantes do sexo masculino dos cursos de Medicina e de Direito em relação a quem deve decidir sobre a realização de um abortamento. Enquanto que entre os estudantes do sexo feminino nāo houve diferença significativa quanto a esta questão, entre os estudantes do sexo masculino foi grande a diferença verificada: $20 \%$ dos alunos do sexo masculino do curso de Medicina responderam que a decisão cabe à mulher, e 73,3\% afirmaram caber ao casal; já entre os estudantes de sexo masculino do curso de Direito, 67,7\% afirmaram caber à mulher, enquanto que $32,3 \%$ responderam que cabe ao casal. Houve praticamente uma inversão.

Embora não se tenham dados suficientes que mostrem claramente o sentido desta diferença, pode-se supor que o estudante de Direito volta-se mais ao aspecto legal da questão, visto que, em se existindo o direito ao abortamento, é a mulher, em última instância, que tem a autonomia da decisão a ser tomada a respeito de seu próprio corpo. Por outro lado, o estudante de 
Medicina vê a questão como tangente ao casal, biologicamente co-responsável pela fecundaçăo ocorrida.

Sem dúvida estes comentários são feitos sem a intençăo de considerar os estudantes que responderam ao questionário como uma amostra válida quer do universo de suas Escolas quer do universo dos estudantes da Universidade de São Paulo.

Para ampliar essa gama de informaçōes os autores já estão planejando abordar outros grupos de estudantes da mesma Universidade, o que será objeto de um proximo trabalho.

MEIRA, A.R. \& FERRAZ, F.R.C. [Freeing of abortion: the opinion of medical and legal students. S.Paulo, Brazil]. Rev. Saúde púbL, S.Paulo, 23: 465-72, 1989.

ABSTRACT: The results of a survey carried out with the participation of 155 medical and 141 law students are given. Of the total of 296 students, 142 agreed with the freeing of abortion from legal restrictions, 144 agreed with such restrictions and 6 gave no opinion. Of the 144, 12 rejected abortion under any circunstances. The differences were analysed by sex and school. The statistical analysis did not show significance at the level of $5 \%$.

KEYWORDS: Abortion, legal. Knowledge, attitudes, practice. Students.

\section{REFERENCIAS BIBLIOGRÁFICAS}

1. FOLHA DE SĀO PAULO. Caderno "Cidades", p. C-2, 27 out. 1988.

2. HOJDA, MJ. Aborto: liberação ou restrição. São Paulo, 1979. [Dissertação de Mestrado - Faculdade de Direito da USP]

3. MARIA, B. \& STAMPF, F. Interruption de la grossesse par l'association mifépristone-sulprostone. Presse méd, 16:2128-9, 1987.

4. MEIRA, AR. Contribuição para o estudo da fertilidade na cidade de Santos, Brasil. Jatros, 4(1):21 4, 1985.

5. OLIVEIRA, J. de, org. Novo codigo penal $23^{\circ}$ ed. São Paulo, Saraiva, 1985.
6. RODGER, M.W. \& BAIRD, D.T. Indiction of therapeutic abortion in early pregnancy with mifepristone in combination with prostoglandin pressary. Lancet, 2:1415-8, 1987.

7. SCHOR, N. Aborto como questâo de saúde pública. São Paulo, 1984. [Tese de Doutorado - Faculdade de Saúde Pública da USP].

Recebido para publicaçāo em 15/2/1989 Reapresentado em 5/7/1989 Aprovado para publicaçäo an 21/7/1989 